\title{
AN EXPERIMENTAL AND MATHEMATICAL SIMULATION OF BIOLOGICAL PROCESSES IN A SEWERAGE SYSTEM
}

\author{
E. GAVALAKIS* \\ D. MAMAIS \\ C. MARINOS \\ A. ANDREADAKIS
}

\author{
${ }^{1}$ National Technical University of Athens, \\ School of Civil Engineering \\ Department of Water Resources, \\ Sanitary Engineering Laboratory SEL
}

Selected from papers presented in $9^{\text {th }}$ International Conference on Environmental Science and Technology (9CEST2005) 1-3 September 2005, Rhodes island, Greece *to whom all correspondence should be addressed Tel.: +30 2107722897 ; Fax: +30 2107722899 e-mail: iukini@central.ntua.gr

\begin{abstract}
Sewer systems may often operate as bioreactors causing considerable wastewater quality changes and in some cases reducing the pollution load conveyed to the treatment plant. Conceptually, transformation of organic matter takes place both in the bulk water (by suspended micro-organisms) and by the sewer biofilm, under aerobic and anaerobic conditions. The most important processes are the hydrolysis of hydrolysable substrate to readily biodegradable substrate and the uptake of the latter for the growth of the biomass (in the form of biofilm and suspended in the liquid) and for maintenance purposes. Depending on whether the critical parameter is the hydrolysis rate or the growth rate of biomass there is a significant increase (former) or decrease (latter) of readily biodegradable substrate.
\end{abstract}

The scope of the work presented herein was to study the processes governing the fate of readily biodegradable substrates in sewer systems in an attempt to verify the mathematical model of a sewerage system developed by Gavalakis et al. (2003) [5]. The specific objectives were to evaluate the effect of (1) biofilm growth, (2) suspended biomass and (3) dissolved oxygen (DO) concentration on readily biodegradable substrate removal.

The experimental results obtained showed that high soluble substrate uptake rates can be observed in sewer systems indicating that sewer systems can act as biological reactors where substantial changes in sewage quality characteristics can occur. Especially for soluble substrates like acetate these changes that take place in the sewer may significantly affect enhanced biological phosphorus removal and denitrification in the wastewater treatment.

The experimental data on soluble substrate removal in sewers showed that the previously developed mathematical model describes in a satisfactory way the kinetics of acetate removal. Acetate removal rates due to biofilm growth did not appear to be influenced by biofilm mass or biofilm thickness. Acetate removal as described by the model appeared to follow a linear correlation between pipe surface to liquid volume (A/V) ratio and soluble COD removal was obtained. In addition acetate uptake rate appeared to increase significantly with increasing DO concentration. The kinetics describing the effect of DO on substrate removal appeared to follow a half order reaction rate throughout the range of DO concentrations studied.

KEYWORDS: Wastewater; gravity sewer; biofilm; acetate removal; organic matter; mathematical modelling. 


\section{INTRODUCTION}

The effectiveness of biological wastewater treatment systems is influenced by the composition of influent wastewater and particularly the relative magnitudes of readily biodegradable, easily hydrolysable and slowly hydrolysable fraction. A change in the composition of influent wastewater may affect the operations of certain biological processes in a wastewater treatment plant. For example, the presence of increased readily biodegradable substrate will positively affect the denitrification and the enhanced biological phosphorus removal processes. On the other hand hydrolysed lipids especially in the form of long chain fatty acids may be responsible for the growth of other filamentous bacteria such as $M$. Parvicella, Type 0092 or Type 0041 [1, 2].

Sewer systems may often operate as bioreactors causing considerable wastewater quality changes and in some cases reducing the pollution load conveyed to the treatment plant. Despite their significance the changes of wastewater quality in gravity sewers have been only recently studied $[3,4,5]$. Conceptually, transformation of organic matter takes place both in the bulk water (by suspended micro-organisms) and by the sewer biofilm, under aerobic and anaerobic conditions. The most important processes are the hydrolysis of hydrolysable substrate to readily biodegradable substrate and the uptake of the latter for the growth of the biomass (in the form of biofilm and suspended in the liquid) and for maintenance purposes. Depending on whether the critical parameter is the hydrolysis rate or the growth rate of biomass there is a significant increase (former) or decrease (latter) of readily biodegradable substrate.

The scope of the work presented herein was to study the processes governing the fate of readily biodegradable substrates in sewer systems in an attempt to verify the mathematical model of a sewerage system developed by Gavalakis et al. (2003) [5]. The specific objectives were to evaluate the effect of (1) biofilm growth, (2) suspended biomass and (3) dissolved oxygen (DO) concentration on readily biodegradable substrate removal.

\section{EXPERIMENTAL MATERIALS AND METHODS}

In order to simulate both hydraulics and biological processes in a sewer, a laboratory scale bioreactor was employed (photo 1). The bioreactor consisted of a $15 \mathrm{~cm}$ diameter rotating plastic cylinder submerged in a tank with an $8 \mathrm{~L}$ liquid volume. The rotating velocity of the cylinder was fixed at $53 \mathrm{rpm}$ resulting in a peripheral velocity of $0.4 \mathrm{~m} / \mathrm{sec}$, which corresponds to a typical wastewater flow in sewers. The rotational speed of the plastic cylinder was monitored by a IKA-Werke, type DZM-M rotational speed meter.

Biofilms were grown during two periods in the bioreactor by daily batch feeding with synthetic wastewater. During the first period a $10 \mathrm{~cm}$ height plastic pipe was employed that corresponded to a sewer pipe surface area to volume ratio (A/V) of $13.5 \mathrm{~m}^{-1}$. During the second period two different $A / V$ ratios were studied equal to $6.73 \mathrm{~m}^{-1}$ and $11.8 \mathrm{~m}^{-1}$. These two $\mathrm{A} / \mathrm{V}$ ratios were achieved by using a plastic pipe with a $5 \mathrm{~cm}$ height that was submerged in a 7 $\mathrm{L}$ and $4 \mathrm{~L}$ liquid volume, respectively. All the experiments were conducted in batch at $a$ constant DO level in the bulk liquid. Oxygen concentration was monitored continuously by an oxygen meter and was maintained constant by regulating the airflow to the liquid. The average biofilm thickness and biofilm biomass were measured during each batch experiment by determination of the wet of the cylinder at the start and at the end of these experiments. The cylinder was drained for $10 \mathrm{~min}$ and then wet weight was determined. By subtracting the weight of the clean cylinder the biofilm thickness was calculated assuming a specific density of $1 \mathrm{~g} / \mathrm{cm}^{3}$ and a total area of the biofilm equal to double the outer surface area of the submerged cylinder. The dry weight of the biofilm was measured periodically by removing a small portion of the biofilm and then measuring total dried solids.

Using this set up, experimental conditions can be varied in terms of a) biofilm surface area to liquid volume ratio, b) concentration and type of substrate, c) wastewater velocity in the sewer and d) DO.

Synthetic wastewater consisted of a sodium acetate solution containing also ammonium chloride and $\mathrm{K}_{2} \mathrm{HPO}_{4}$ as sources of nitrogen and phosphorus respectively. The synthetic wastewater concentrations were approximately $400 \mathrm{mg} \mathrm{l}^{-1} \mathrm{COD}, 40 \mathrm{mg} \mathrm{I}^{-1} \mathrm{~N}$, and $5 \mathrm{mg} \mathrm{I}^{-1} \mathrm{P}$. Using this experimental set up the rate of readily biodegradable substrate consumption, due 
to biofilm and suspended biomass was determined under different environmental conditions, such as fully aerobic conditions, fairly low dissolved oxygen conditions $\left(1.0 \mathrm{mg} \mathrm{l}^{-1}-2.0 \mathrm{mg} \mathrm{l}^{-1}\right)$ and very low dissolved oxygen conditions $\left(0.1 \mathrm{mg} \mathrm{l}^{-1}-0.5 \mathrm{mg} \mathrm{l}^{-1}\right)$.

All COD, TSS, VSS analyses were conducted according to Standard Methods (1992) [6].



Photo 1. Bioreactor employed for the simulation of processes in sewer systems

\section{MATHEMATICAL MODELLING OF THE PROCESSES}

The processes that have been considered during the mathematical modelling of a sewerage system are the following [5]:

a Reaeration

- Heterotrophic growth of biomass in liquid

a Maintenance energy requirement of suspended biomass

口 Biofilm growth

a Hydrolysis

In the context of the present work the mathematical model can be simplified since all the experiments aimed to evaluate the effect of various parameters on readily biodegradable substrate removal. Thus its application was limited to the description of the following processes that are related to readily biodegradable substrate removal:

Heterotrophic growth of biomass in liquid: The concept of heterotrophic growth as expressed through the classical Monod equation is used (equation (1)). Biomass growth ( $\mathrm{X}_{\mathrm{BW}}$ ) in aerobic conditions results in the reduction of readily biodegradable substrate $\left(\mathrm{S}_{S}\right)$.

Aerobic growth in biomass $=\mu_{\mathrm{H}} \mathrm{S}_{\mathrm{S}} /\left(\mathrm{K}_{\mathrm{S}}+\mathrm{S}_{\mathrm{S}}\right) \mathrm{S}_{\mathrm{o}} /\left(\mathrm{K}_{\mathrm{o}}+\mathrm{S}_{\mathrm{o}}\right) \mathrm{X}_{\mathrm{Bw}} 1.07^{\mathrm{T}-20}$

where $\mu_{H} \quad$ maximum specific growth rate $\left(d^{-1}\right)$

$\mathrm{S}_{\mathrm{O}} \quad$ dissolved oxygen concentration $\left(\mathrm{g} \mathrm{m}^{-3}\right)$

$\mathrm{K}_{\mathrm{S}} \quad$ saturation constant for readily biodegradable substrate $\left(\mathrm{g} \mathrm{COD} \mathrm{m}^{-3}\right)$

$\mathrm{K}_{\mathrm{O}} \quad$ saturation constant for $\mathrm{DO}\left(\mathrm{g} \mathrm{O}_{2} \mathrm{~m}^{-3}\right)$

Maintenance energy requirement of suspended biomass: The maintenance energy requirement concept (equation (2)) as opposed to the high biomass decay rate is considered reasonable in a sewer system where the biomass often exist under organic carbon conditions of unlimited growth [7]. The concept accounts for a maintenance energy requirement of the biomass, which in addition to the growth related energy requirement, removes readily biodegradable substrate and if this is not available the biomass itself by lysis. 
Maintenance energy requirement rate $=\mathrm{q}_{\mathrm{m}} \mathrm{S}_{\mathrm{o}} /\left(\mathrm{K}_{\mathrm{o}}+\mathrm{S}_{\mathrm{o}}\right) \mathrm{X}_{\mathrm{BW}} 1.07^{\mathrm{T}-20}$

where $q_{m} \quad$ maintenance energy requirement rate constant $\left(d^{-1}\right)$

Biofilm growth: A simple expression (equation (3)) for biofilm growth and respiration is used to describe the phenomenon. With respect to removal rates half order kinetics has been considered as a reasonable approximation for biofilm [7].

Aerobic growth in biofilm $=k_{1 / 2} S_{O}{ }^{0.5} Y_{H f} /\left(1-Y_{H f}\right) A / V ~ S_{S} /\left(K_{S f}+S_{S}\right) 1.07^{T-20}$

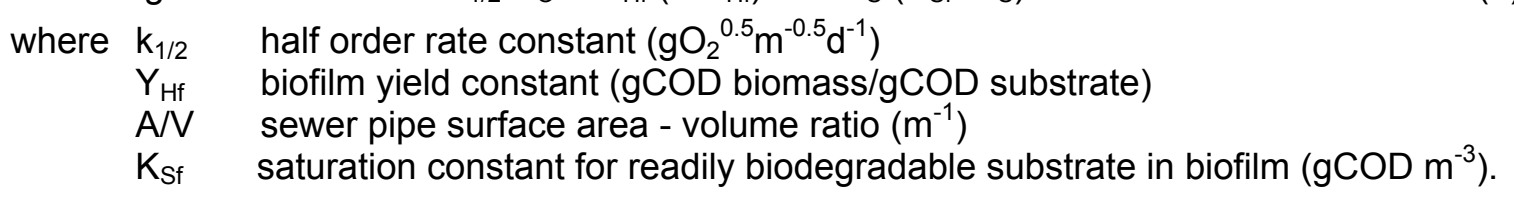

The process matrix describing the transformation of readily biodegradable organic matter in a gravity sewer based on the previous equations is presented in Table 1.

Table 1. Integrated processes of the fate of organic matter in a sewer system

\begin{tabular}{lcccc}
\hline \multicolumn{1}{c}{ Components } & $\mathrm{S}_{\mathrm{S}}$ & $\mathrm{X}_{\mathrm{B}}$ & $\mathrm{S}_{\mathrm{O}}$ & Equation \\
\hline Process & & & $\left(1-\mathrm{Y}_{\mathrm{HW}}\right) /$ & $(1)$ \\
$\begin{array}{l}\text { Suspended biomass } \\
\text { Maintenance energy }\end{array}$ & $-1 / \mathrm{Y}_{\mathrm{HW}}$ & 1 & $\mathrm{Y}_{\mathrm{HW}}$ & 1 \\
$\begin{array}{l}\text { requirement } \\
\text { Biofilm }\end{array}$ & -1 & & $12)$ \\
\hline
\end{tabular}

\section{RESULTS AND DISCUSSION}

The experiments presented herein aimed to evaluate the effects of (1) biofilm growth, (2) suspended biomass and (3) dissolved oxygen (DO) concentration on readily biodegradable substrate removal, in an attempt to verify the mathematical model of a sewerage system presented previously [5]. All the experiments were conducted at high soluble COD concentrations. During each experiment the following parameters were monitored:

口 DO concentration

- Soluble COD removal

a Biofilm and suspended biomass

\section{Effect of biofilm biomass on acetate removal rate}

In order to evaluate the effect of biofilm thickness and biofilm mass on acetate removal rate, a series of batch experiments were conducted at high DO and acetate concentrations so that neither DO nor readily biodegradable COD would limit acetate removal rate. Acetate removal rate due to biofilm growth was determined by subtracting the removal due to suspended biomass from the obtained total acetate removal rate. Acetate removal due to suspended solids was measured during batch experiments with no biofilm and was equal to $0.8 \mathrm{mg}$ acetate/mg suspended biomass $-\mathrm{hr}$.

Acetate removal rates due to biofilm growth are shown as a function of biomass thickness and total biofilm biomass in Figures 1 and 2. According to the experimental data both parameters did not appear to influence acetate removal. Only at the beginning of biofilm growth when the cylinder was not completely covered with biofilm did acetate removal rate depend on biofilm thickness and mass. The average acetate removal rate due to biofilm growth, measured in terms of soluble COD was $20.8 \mathrm{mg} \mathrm{COD} / \mathrm{L}-\mathrm{hr}(\mathrm{n}=8$, Std. dev. $=2.7 \mathrm{mg}$ COD L $\left.\mathrm{L}^{-1} \mathrm{hr}^{-1}\right)$.

The effect of sewer pipe surface area to volume ratio $(A / V)$ on the readily biodegradable COD removal rate was assessed by conducting batch experiments at various $A / V$ ratios. All batch experiments were conducted at high initial acetate concentration (400 $\mathrm{mg} \mathrm{l}^{-1}$ soluble COD) and high DO $\left(5-6 \mathrm{mg} \mathrm{l}^{-1}\right)$ level. As shown in Figure 3 a linear correlation between A/V ratio and soluble COD removal was obtained similar to the one described by equation [3]. 


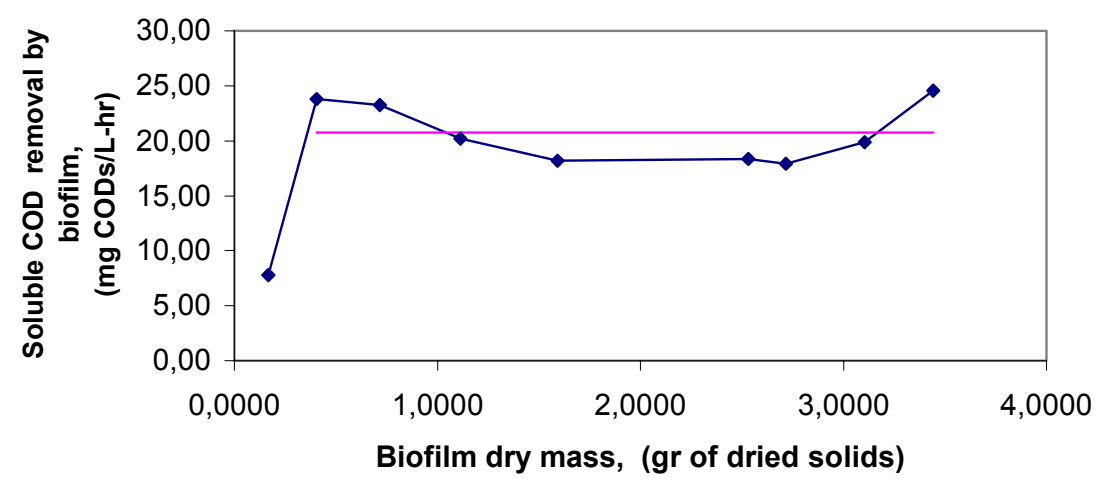

Figure 1. Effect of biofilm biomass on readily biodegradable substrate removal rate

\section{Effect of DO level on acetate removal rate}

Figure 4 shows the effect of $\mathrm{DO}$ level on acetate removal rates expressed in terms of soluble COD uptake for all the experiments conducted. Acetate concentration in the bioreactor throughout the duration of each experiment was kept high and non-limiting (acetate concentration greater than $100 \mathrm{mg} \mathrm{I}^{-1}$ ). In order to evaluate the effect of DO on acetate removal the following three different ranges of DO were studied:

High DO level - DO = 4-7 $\mathrm{mg} \mathrm{I}^{-1}$
Medium DO level - DO = $1-2 \mathrm{mg} \mathrm{I}^{-1}$
Low DO level - DO $=0.1-0.5 \mathrm{mg} \mathrm{l}^{-1}$

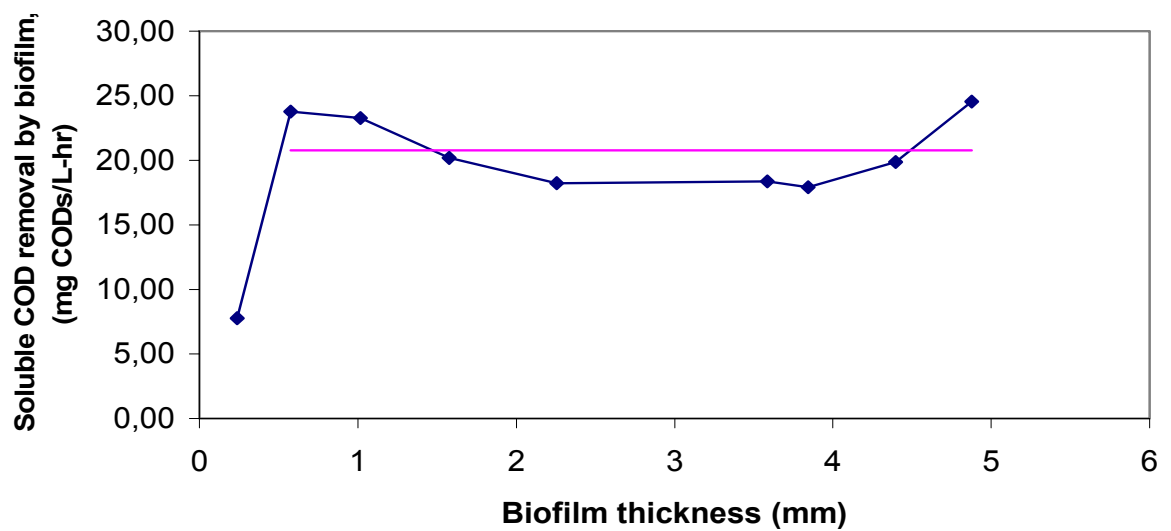

Figure 2. Effect of biofilm thickness on readily biodegradable substrate removal rate

The acetate uptake rate appeared to increase significantly when the DO concentration was raised from the low to medium DO concentration range, $0.2-1.3 \mathrm{mg} \mathrm{l}^{-1}$, to the high range, 5.9 $-7.4 \mathrm{mg} \mathrm{l}^{-1}$. As shown in Figure 4 the effect of DO on soluble substrate uptake can be described by linearization of equation [3]:

Acetate removal rate due to biofilm growth $=0.70 \times \mathrm{DO}^{0.5}\left(\mathrm{r}^{2}=0.9537\right)$

The kinetics describing the effect of DO on substrate removal appeared to follow a half order reaction rate, as described by the mathematical model. According to the experimental data DO limitation occurred throughout the range of DO levels studied indicating that the biofilm was only partially penetrated by oxygen. 


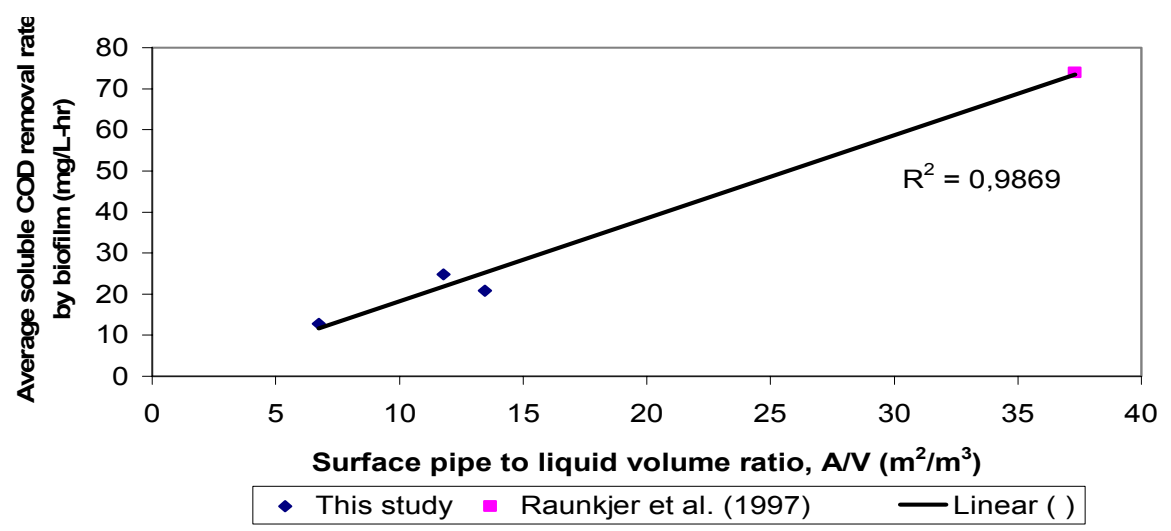

Figure 3. Effect of biofilm surface to liquid volume ratio on readily biodegradable substrate removal rate

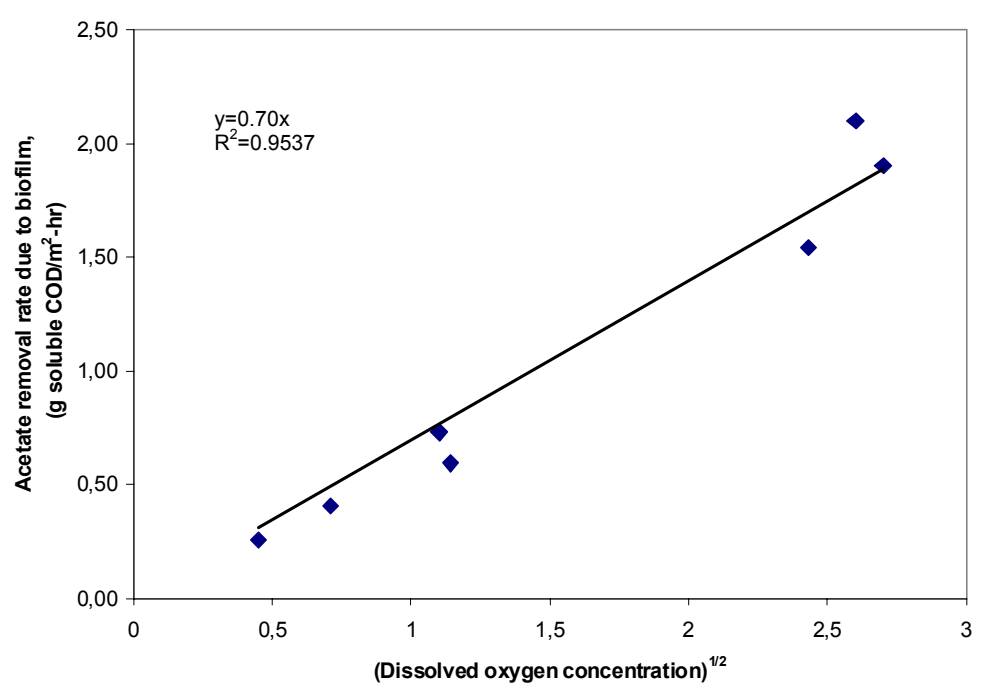

Figure 4. Effect of dissolved oxygen concentration on average acetate removal rate

\section{CONCLUSIONS}

The main conclusions of the present work can be summarized as follows:

a The observed high soluble substrate uptake rates underlines that the sewer system is a biological reactor where substantial changes in sewage quality characteristics can occur. Especially for soluble substrates like acetate these changes that take place in the sewer may significantly affect enhanced biological phosphorus removal and denitrification in the wastewater treatment.

- Acetate removal rates due to biofilm growth did not appear to be influenced by biofilm mass or biofilm thickness. Only at the beginning of biofilm growth when the cylinder was not completely covered with biofilm did acetate removal rate depend on biofilm thickness and mass.

- A linear correlation between pipe surface to liquid volume $(A / V)$ ratio and soluble COD removal was obtained.

- Acetate uptake rate appeared to increase significantly with increasing DO concentration. The kinetics describing the effect of DO on substrate removal appeared to follow a half order reaction rate throughout the range of DO concentrations studied, indicating that DO limitation occurred and that the biofilm was only partially penetrated by oxygen.

- According to the experimental data the mathematical model developed [5] predicts in a satisfactory way the parameters that affect soluble substrate uptake in a sewer system. 


\section{ACKNOWLEDGMENTS}

Thanks are due to the director of the Municipal Enterprise for Water and Sewage of loannina and the personnel of the wastewater treatment plant of loannina for their cooperation and involvement in the project.

The paper presents the results of a wider work conducted in the framework of Action 8.3 of the Competitiveness Programme-PENED (2000-2006) sponsored by the European Union $75 \%$ and the Greek Secretariat for Research $25 \%$.

\section{REFERENCES}

1. Noutsopoulos C., (2002) Assessment of the effect of alternative treatment schemes on the settling characteristics of nutrient removal activated sludge systems NTUA - PhD Thesis.

2. Mamais D., Andreadakis A., Noutsopoulos C. and Kalergis C. (1998) Causes of and Control Strategies for Microthrix parvicella Bulking and Foaming in Nutrient Removal Activated Sludge Systems Wat.Sci.Tech., 37(4/5), 9-17.

3. Tanaka N. and Hvitved-Jacobsen T. (1998) Transformations of wastewater organic matter in sewers under changing aerobic/anaerobic conditions, Wat. Sci. Tech., 37(1), 105-113.

4. Hvitved-Jacobsen T., Vollertsen J. and Nielsen P.H., (1998) A process and model concept for microbial wastewater transformations in gravity sewers, Wat. Sci. Tech., 37(1), 233-241.

5. Gavalakis, E., Andreadakis, A. (2003) Fate of sewage organic load in a sewerage system, $8^{\text {th }}$ International conference on the Protection of the Environment, Limnos, Greece.

6. APHA - AWWA - WPCF (1992), Standard methods for the examination of Water and Wastewater, $18^{\text {th }}$ edition, New York.

7. Bjerre H. L., Hvitved-Jacobsen T., Schlegel S. and Teichgraber B., (1998) Biological activity of biofilm and sediment in the Emscher river, Germany, Wat. Sci. Tech., 37(1), 9-16. 